\title{
Pyoderma gangrenosum affecting the mouth
}

\author{
Marcos Martins Curi ${ }^{1}$, Camila Lopes Cardoso ${ }^{1,2^{*}}$, Daniel Henrique Koga ${ }^{1}$, Cristina Zardetto ${ }^{1}$, \\ Sérgio Rocha Araújo ${ }^{1}$ \\ ${ }^{1}$ Department of Stomatology, Hospital Santa Catarina, São Paulo, Brazil \\ ${ }^{2}$ Department of Stomatology, Bauru School of Dentistry, University of São Paulo, Bauru, São Paulo, Brazil \\ Email: cardoso_lopes@yahoo.com.br
}

Received 8 February 2013; revised 25 April 2013; accepted 8 May 2013

Copyright (C 2013 Marcos Martins Curi et al. This is an open access article distributed under the Creative Commons Attribution License, which permits unrestricted use, distribution, and reproduction in any medium, provided the original work is properly cited.

\begin{abstract}
Pyoderma gangrenosum is a rare ulcerative cutaneous disorder commonly associated with systemic diseases such as inflammatory bowel diseases. This paper reports a case of pyoderma gangrenosum affecting the mouth and the skin associated with ulcerative colitis. A Medline search in English literature from 1961 to 2012 revealed only 11 documented cases of pyoderma gangrenosum with oral involvement. Previous reported cases of oral cavity involvement have shown that the most common sites of manifestation are the tongue, palate, and tonsillar fauces. This case emphasizes the importance of including inflammatory bowel diseases and their manifestations in the differential diagnosis of ulcerative lesions in the oral cavity.
\end{abstract}

Keywords: Pyoderma Gangrenosum; Oral Manifestation; Inflammatory Bowel Disease; Ulcerative Colitis

\section{INTRODUCTION}

Pyoderma gangrenosum (PG) is a rare disorder of skin commonly associated with systemic diseases such as inflammatory bowel diseases (IBD), haematological disorders and autoimmune disease [1]. PG has been reported to occur in about a third of the IBD population [1]. Although its etiology still unknown it may be an autoimmune disorder. Clinically, this disorder is characterized by painful papulopustules which can progress to large and irregular ulcerations [1,2]. PG may affect any part of the body, but there are more common sites of involvement such as lower extremities, buttocks, abdomen, face and rarely forehead, scrotum and eyes [2,3]. Oral involvement is rare, but ulcerations may appear as a manifestation of this disease [4]. A Medline search in English literature from 1961 to 2011 revealed only 11 documented cases of PG with oral involvement and this case

\footnotetext{
"Corresponding author.
}

report illustrates a new occurrence associated with Ulcerative Colitis (UC) [1,2,4-10] (Table 1).

\section{CASE REPORT}

A 58-year-old male was referred sought our Hospital presenting signs of active UC (diarrhea, melena, abdominal pain), which had been diagnosed fifteen years ago. Physical examination revealed multiple purulent necrotic ulcers spread by skin tissue of trunk, limbs, face, and eyelid (Figure 1). These lesions were clinically diagnosed as PG by dermatologist. Intraoral examination revealed an extensive vegetative ulceration surrounded by an erythematous halo on the left side of the soft palate and tonsillar pillar, measuring about $3.0 \times 2.0 \mathrm{~cm}$ in size, symptomatic and recovered by a yellowish pseudomembrane (Figure 2(A)). In addition, another superficial ulceration was identified on the right side of the tongue, but different from the ulcer of the palate (Figure 2(B)). The patient lost $8 \mathrm{~kg}$ during one month since the disease started and the laboratory tests revealed white blood cell count $15,900 / \mathrm{mm}^{3}$; red blood cell count $4.17 \times 10^{6} / \mathrm{mm}^{3}$; and an increased of platelet count $598 \times 10^{3} / \mathrm{mm}^{3}$; glutamic oxaloacetic transaminase, $28 \mathrm{IU} / \mathrm{L}$; glutamate pyruvate transaminase, $25 \mathrm{IU} / \mathrm{L}$. The C-reactive protein was 20.34 $\mathrm{mg} / \mathrm{dL}$ and erythrocyte sedimentation rate $71 \mathrm{~mm}$. The patient was submitted to colonoscopy which showed flare-up colitis involving the entire colon followed by an incisional biopsy. The microscopy showed nonspecific inflammatory cell infiltration including neutrophils and lymphocytes and no granulomatous lesions were observed (Figure 3(A)). Incisional biopsy of the skin trunk lesion was performed which showed non-specific suppurative inflammatory lesion with infiltration of neutronphils and lymphocytes in the connective tissue with some necrosed blood vessel (Figure 3(B)). The diagnosis was ulcerative colitis (UC) and pyoderma gangrenosum (PG) for oral and skin lesions, respectively. Treatment consisted of controlling the underlying inflammatory bowel 
Table 1. Cases of PG with oral involvement reported in the literature.

\begin{tabular}{|c|c|c|c|c|c|}
\hline Case reports & Sex/Age & Oral Site & $\begin{array}{l}\text { Associated Systemic } \\
\text { Diseases }\end{array}$ & Oral Biopsy & Treatment \\
\hline \multirow{2}{*}{$\begin{array}{l}\text { Margoles \& Wenger, } \\
1961\end{array}$} & $\mathrm{M} / 28$ & Palate & UC & $\begin{array}{l}\text { Non-specific chronic } \\
\text { ulceration }\end{array}$ & Prednisolone $30 \mathrm{mg}$ daily \\
\hline & $\mathrm{M} / 23$ & Palate & $\mathrm{UC}$ & NP & Cortisone 300 mg daily \\
\hline \multirow{2}{*}{ Basu \& Asquith, 1970} & NI & NI & UC & NI & NP \\
\hline & NI & NI & UC & NI & NP \\
\hline Yusuf \& Ead, 1985 & $\mathrm{M} / 61$ & Tongue & NI & NP & Prednisolone 100 mg daily \\
\hline Snyder, 1986 & $\mathrm{~F} / 29$ & Oral mucosa & ANA 1:80 & NP & $\begin{array}{l}\text { Prednisolone } 80 \text { mg daily, pulsed } \\
\text { methyl prednisolone } \\
50 \text { mg twice daily, dapsone } \\
100 \text { mg once daily } \\
\text { intralesional } \\
\text { triamcinolone weekly. }\end{array}$ \\
\hline Kennedy et al., 1987 & $\mathrm{~F} / 54$ & Tongue & IBD, Hepatitis B & $\begin{array}{l}\text { Mucosal ulceration, } \\
\text { Necrosis, mixed } \\
\text { inflammatory infiltrate: } \\
\text { predominantly } \\
\text { neutrophils }\end{array}$ & $\begin{array}{l}1 \mathrm{~g} \text { pulsed methyl } \\
\text { prednisolone for } 5 \text { days, } \\
\text { prednisolone } 30 \mathrm{mg} \\
\text { alternate days }\end{array}$ \\
\hline Yco et al., 1988 & $\mathrm{M} / 62$ & Palate & $\begin{array}{l}\text { Polycythaemia rubra } \\
\text { vera }\end{array}$ & $\begin{array}{l}\text { Focal necrosis, small } \\
\text { vessel vasculitis }\end{array}$ & $\begin{array}{l}\text { Intralesional } \\
\text { Triamcinolone and } \\
\text { Prednisolone }\end{array}$ \\
\hline Setterfield et al., 2001 & $\mathrm{M} / 54$ & $\begin{array}{l}\text { Palate, oropharynx, } \\
\text { tongue and comis } \\
\text { sure of lip }\end{array}$ & IgA paraproteinaemia & $\begin{array}{l}\text { Mucosal ulceration, } \\
\text { neutrophilic infiltrate } \\
\text { in the lamina propria } \\
\text { and a mixed } \\
\text { inflammatory cell } \\
\text { infiltrate in the corium }\end{array}$ & $\begin{array}{l}\text { Methyl } \\
\text { prednisolone and } \\
\text { Cyclophosphamide }\end{array}$ \\
\hline Hiromi, 2008 & $\mathrm{~F} / 47$ & Buccal mucosa & Behçet disease & NP & $\begin{array}{l}\text { Prednisolone } 15 \text { mg daily } \\
\text { Colchicine } 1 \text { mg daily }\end{array}$ \\
\hline $\begin{array}{l}\text { Paramkusam et al., } \\
2010\end{array}$ & $\mathrm{~F} / 45$ & Palate & PG & $\begin{array}{l}\text { Chronic, non-specific } \\
\text { suppurative inflammatory } \\
\text { lesion }\end{array}$ & $\begin{array}{l}\text { Metronidazole, Chlorhexidine } \\
\text { mouth rinse, Prednisolone } 30 \mathrm{mg} \\
\text { daily and Dapsone }\end{array}$ \\
\hline $\begin{array}{l}\text { Curi et al. } \\
\text { (present case) }\end{array}$ & $\mathrm{M} / 48$ & Palate and tongue & UC & NP & $\begin{array}{l}\text { Prednisolone } 40 \text { mg daily, } \\
\text { Mesalamine } 4 \text { mg daily, Oxacillin } \\
2 \text { g daily }\end{array}$ \\
\hline
\end{tabular}

NP: Not Performed; NI: Not Informed; UC: Ulcerative Colitis.

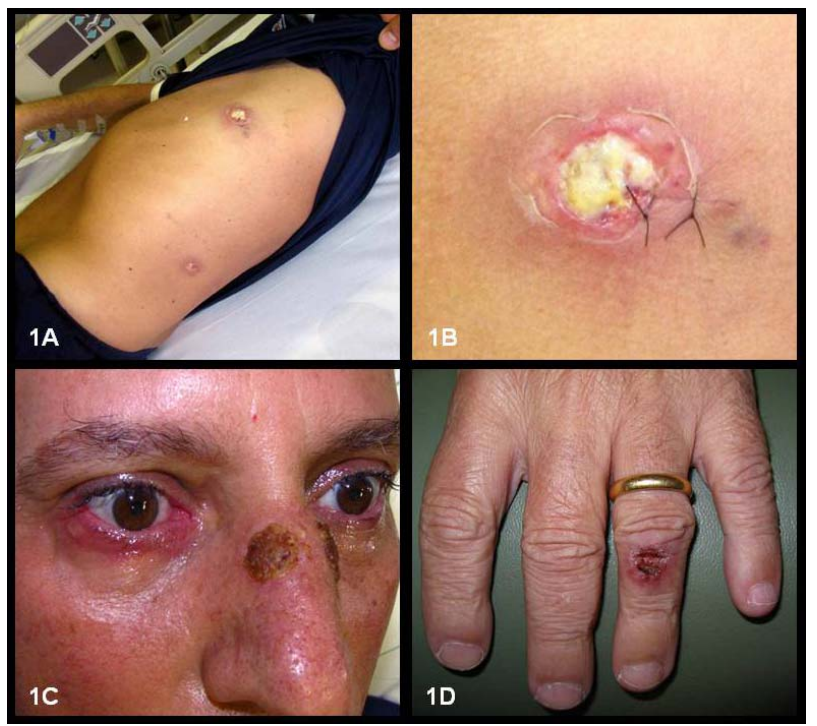

Figure 1. Clinical aspects of skin lesions. (A) Lesions affecting the chest; (B) Detail of the lesion; (C) Lesions in the face, eyes and (D) finger.

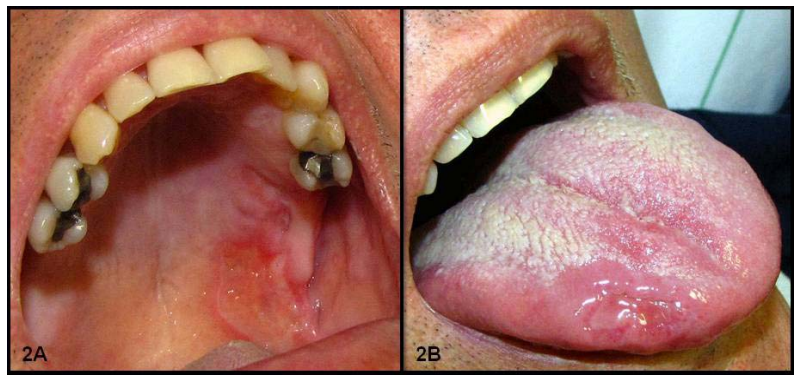

Figure 2. (A) Clinical aspects of oral lesions; (B) Ulceration in palate and tongue.

disease using systemic steroid therapy (Prednisolone 40 mg daily) and (Mesalazine $800 \mathrm{mg}$ daily) associated with antibiotic therapy (Oxacillin 2 g daily). The oral lesions were managed with local therapies using Chlorexidine $0.12 \%$ mouthwash and topical corticosteroids. After a week of treatment, we observed rapid and complete resolution of the mucocutaneous lesions, as well as the signs and symptoms of UC (Figure 4). 


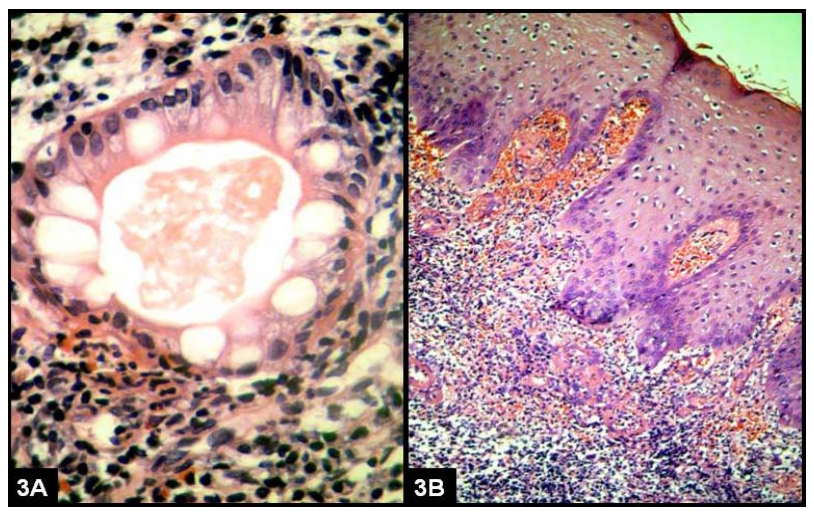

Figure 3. Photomicrography of colonoscopy and biopsy of the skin, respectively. (A) Intense inflammatory infiltrate composed of polymorphonuclear cells, plasmocytes and few eosinophils causing disruption of the glandular tissue colonic; (B) Hyperplastic stratified squamous epithelium with acanthosis and focal subepithelial hemorrhage. The connective tissue revelead an intense and diffuse inflammatory infiltrate with some neutrophils and plasmocytos in perivascular areas (HE).

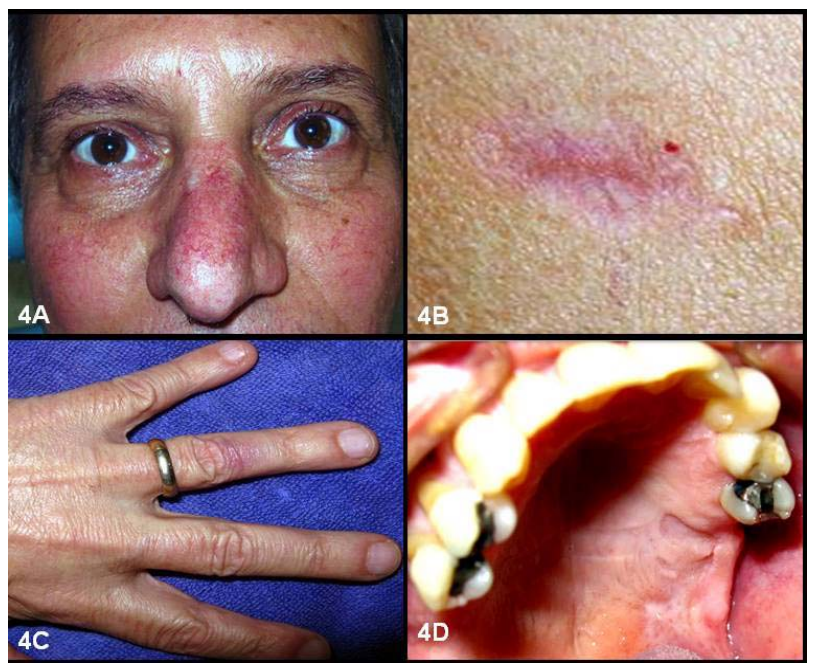

Figure 4. 3 months follow-up showing the remission of mucocutaneous lesions.

\section{DISCUSSION}

Pyoderma gangrenosum (PG) is a rare neutrophilic dermatosis first described by Bursting et al. [11], in 1930, who published 5 patients with skin lesions and 4 of whom associated with Ulcerative Colitis (UC). It is characterized by recurrent cutaneous ulcerations commonly associated with systemic disease (inflammatory bowel disease (IBD), rheumathoid arthritis, inflammatory polyarthritis, myeloma, paraproteinemia, polycythemia vera, acute and chronic myelogenous leukemia, chronic hepatitis and Behçet's syndrome), while in $40 \%$ - 50\% cases no systemic disease is observed [1]. Skin lesions have been described as ulcerative lesions with central necrosis and irregular violaceous border tenderness with under- mined rolled edges. Also, they can be solitary, multiple or present different clinical aspects [4]. It predominately occurs in adults between the ages of 20 - 50 years and rarely affects children [4]. Because the microscopic findings of PG and the laboratory tests are nonspecific, the diagnosis is based primarily on its clinical manifestations. In our case, PG was diagnosed through clinical examination by a dermatologist and it was confirmed by microscopic findings.

UC presents a slight male predilection, significant morbidity, but low mortality [12]. The main signs are chronic diarrhea with blood, weight loss, fatigue and abdominal pain. Criteria for diagnosis of UC is based on clinical findings, colonoscopy and sampling of intestinal mucosa. In this case, diagnosis of UC was done 15 years ago through the above mentioned examinations and this was the first time period associated with PG. Despite of the previous medical history, a new colonoscopy with colon biopsy and laboratory tests confirmed the diagnosis of UC.

In patients with inflammatory bowel diseases (IBD), PG occurs in approximately $5 \%$ of cases with UC. Our case shows this well recognized association found in the literature. Extraintestinal manifestations of the IBD are common and they can be found in $6 \%-47 \%$ of cases reported [12]. Oral involvement of PG is very rare [4]. There are only 11 reported cases (Table 1) of PG involving oral cavity in the literature [1,2,4-10]. Oral lesions in PG are characterized by irregular shaped ulcers of varying sizes in diameter with rolled out margins and a grayish colored base and affect mainly the tongue, soft and hard palate [1,2,4-10]. Where oral lesions occur in association with IBD, they should be differentiated from other oral ulcers such as aphthous ulcers and pyostomatitis vegetans (PV) [12]. PV is another rare condition which can develop in association with UC and is characterized by pustules, erosions and vegetative plaques in the oral cavity [2]. The histopathological features of PV are very characteristic [2] and show hyperkeratosis and acanthosis intraepithelial abscesses and a prominent eosinophilic and neutrophilic infiltrate in the lamina propria [5]. Since the first reports of PV, approximately 37 cases have been documented in the literature [13].

Previous cases report of oral cavity involvement in patients with PG have shown that the most common sites of manifestation are the tongue, palate, and tonsillar fauces. Among these 11 previous reported cases, 5 patients developed oral lesions on the palate and 3 patients had lesions on the tongue. In this review, PG was associated with IBD in 5 patients, usually UC.

The treatment of the oral lesions depends on the correct diagnosis of the systemic disease and appropriate selection of local and systemic therapies. When PG ulcerative condition is well established, it is essential to 
investigate super added microbial infection by haematological and swab cultures to treat with appropriate antibiotics [14]. In our case, the treatment consisted of systemic therapy, involving corticosteroids and Mesalazine to control the IBD, associated with antibiotic therapy to treat the super added infection. After one week of treatment, the systemic therapy resulted in a complete and fast resolution of the mucocutaneous lesions. In addition, the oral lesions were managed with antiseptic and topical corticosteroids mouthwashes.

Finally, although the oral involvement of PG is very rare, it should be considered in patients with IBD and skin ulcers. This case emphasizes the importance to consider this entity as differential diagnosis of ulcerative lesions in the oral cavity.

\section{REFERENCES}

[1] Yco, M.S., Warnock, G.R., Cruickshank, J.C. and Burnnet, J.R. (1988) Pyoderma gangrenosum involving the head and neck. Laryngoscope, 98, 765-768. doi:10.1288/00005537-198807000-00016

[2] Setterfield, J.F., Shirlaw, P.J., Challacombe, S.J. and Black, M.M. (2001) Pyoderma gangrenosum associated with severe oropharyngeal involvement and IgA paraproteinaemia. British Journal of Dermatology, 144, 393-396. doi:10.1046/j.1365-2133.2001.04035.x

[3] Callen, J.P. (1998) Pyoderma gangrenosum. Lancet, 351, 581-585. doi:10.1016/S0140-6736(97)10187-8

[4] Paramkusam, G., Meduri, V. and Gangeshetty, N. (2010) Pyoderma gangrenosum with oral involvement-Case report and review of the literature. International Journal of Oral Science, 2, 111-116. doi:10.4248/IJOS10032

[5] Basu, M. and Asquith, P. (1980) Oral manifestations of inflammatory bowel disease. Journal of Clinical Gastroenterology, 9, 307-321.
[6] Margoles, J.S. and Wenger, J. (1961) Stomal ulceration associated with pyoderma gangrenosum and ulcerative colitis. Report of two cases. Gastroenterology, 41, 594598.

[7] Kennedy, K.S., Prendergast, M.L. and Sooy, C.D. (1987) Pyoderma gangrenosum of the oral cavity, nose and larynx. Otolaryngology—Head and Neck Surgery, 97, 487490.

[8] Snyder, R.A. (1986) Pyoderma gangrenosum involving the head and neck. Archives of Dermatology, 122, 295302. doi:10.1001/archderm.1986.01660150073019

[9] Hiromi, T. (2008) Case of pyoderma gangrenosum showing oral and genital ulcers, misdiagnosed as Behcet's disease at first medical examination. The Journal of Dermatology, 35, 289-292. doi:10.1111/j.1346-8138.2008.00468.x

[10] Yusuf, H. and Ead, R.D. (1985) Pyoderma gangrenosum with involvement of the tongue. British Journal of Oral and Maxillofacial Surgery, 23, 241-250. doi:10.1016/0266-4356(85)90040-3

[11] Burnsting, L.A., Goeckrman, W.H. and O’Leary, P.A. (1930) Pyoderma (ecthyma) gangrenosum: Clinical and experimental observations in five cases occurring in adults. Archives of Dermatology, 22, 655-690. doi:10.1001/archderm.1930.01440160053009

[12] Fatahzadeh, M. (2009) Inflammatory bowel disease. Oral Surgery, Oral Medicine, Oral Pathology, Oral Radiology, and Endodontology, 108, 1-10. doi:10.1016/j.tripleo.2009.07.035

[13] Ruiz-Roca, J.A., Berini-Aytés, L. and Gay-Escoda, C. (2005) Pyostomatitis vegetans. Report of two cases and review of the literature. Oral Surgery, Oral Medicine, Oral Pathology, Oral Radiology, and Endodontology, 99, 447-454. doi:10.1016/j.tripleo.2003.08.022

[14] Mani, V. (2002) Pyoderma gangrenosum. The International Journal of Lower Extremity Wounds, 1, 43. doi:10.1177/153473460200100106 